\title{
O USO DA REDE SOCIAL FACEBOOK PARA O MARKETING: 0 caSo da
}

\section{Amicci Moda}

Thaiza Salgado da CRUZ ${ }^{1}$

Marcelo Aureliano Monteiro de ANDRADE ${ }^{2}$

Marlusa de Sevilha GOSLING ${ }^{3}$

Iury Teixeira de Sevilha GOSLING

\author{
${ }^{1}$ Administradora de Empresa (UFMG). Analista Executiva de Defesa Social (SEDS / MG). thaizacruz@ yahoo.com.br \\ ${ }^{2}$ Publicitário (PUC-MG), Mestre e Doutor em Administração (UFMG). Professor da \\ UninCor.aureliano.marcelo@yahoo.com.br \\ ${ }^{3}$ Analista de Sistemas, Mestre e Doutora em Administração (UFMG). Professora Associada da UFMG. \\ mg.ufmg@gmail.com \\ ${ }^{4}$ Administrador (UNICESUMAR). Pesquisador do NEECIN - TUR (UFMG). iurygosling@gmail.com
}

Recebido em: 09/02/2017 - Aprovado em: 20/08/2017 - Disponibilizado em: 30/12/2017

\begin{abstract}
RESUMO:
Este trabalho analisou o uso do Facebook na estratégia de marketing de uma loja de moda feminina, tendo em vista os seguintes construtos: relacionamento, comunicação de marketing e marca. O objeto de estudo foi a página no Facebook da marca de moda Amicci, localizada em Belo Horizonte, Minas Gerais. Foi realizado um estudo qualitativo e exploratório. A coleta de dados aconteceu a partir de entrevistas com a proprietária da Amicci e com sete usuárias do Facebook que "curtem" a página da marca e interagem com seu conteúdo. A observação semanal e posterior análise da página da loja serviram como contraponto às entrevistas. Dentre os aspectos observados, destacam-se a atitude positiva e proativa da Amicci no relacionamento com suas consumidoras no ambiente do Facebook e a importância dessa rede social para a publicidade boca-a-boca da loja. Adicionalmente, a pesquisa constatou que a imagem e posicionamento da marca passadas por meio de sua página no Facebook são condizentes com sua realidade. Isso demonstra que os objetivos da estratégia de comunicação em Facebook da Amicci são alcançados.
\end{abstract}

Palavras-chave: marketing de relacionamento, comunicação de marketing, marca, moda, Facebook.

\section{ABSTRACT:}

This study examined the use of Facebook in marketing strategy of a female fashion store in order constructs: relationship, marketing communications and brand. The object of study was the Facebook page of Amicci fashion brand, located in Belo Horizonte, Minas Gerais. We conducted a qualitative and exploratory study. Data collection took place from interviews with the owner of Amicci and seven users of Facebook who "like" the brand page and interact with it's content. The weekly observation and subsequent analysis of the store page served as a counterpoint to the interviews. Among the features observed, we highlight the positive and proactive attitude of Amicci relationship with their consumers in the Facebook environment and the importance of social networking for advertising word-of-mouth Store. Additionally, the survey found that the image and brand positioning passed throughits Facebook page are consistent with their reality. This demonstrates that the goals of Amicci's Facebook communication strategy are achieved.

Keywords: relationship marketing, marketing communications, brand, fashion, Facebook.

\section{INTRODUÇÃO}

A tecnologia tem se tornado aspecto essencial para a vantagem competitiva das organizações (CRAVENS; PIERCY, 2007). Atualmente, na era da internet, o marketing está sendo redefinido. A internet permitiu o surgimento de processos mais eficientes e eficazes - desenvolvendo um novo canal de relacionamento, de comunicação e de gerência da marca - o que incrementou os 
aspectos dos negócios (TOLEDO et. al., 2004). A relação empresa/produtos/clientes é cada vez mais interativa.

Um dos grandes desafios hoje, portanto, consiste em capturar as vantagens da internet aplicando os conceitos de marketing: o chamado marketing digital. Algumas das ferramentas que vêm ganhando força nos últimos anos são as redes sociais virtuais Facebook, Twitter, Youtube, Instagram, entre outras. Essas redes são plataformas normalmente gratuitas e de fácil uso, que oferecem um espaço virtual para escrever e compartilhar conteúdos com outras pessoas da mesma rede de contatos (REIS et. al., 2009) e são utilizadas para vários propósitos: lazer, comunicação, canal de informação, campanha política, comércio, etc (KOZESINSKI; et. al., 2011).

Com a popularização das redes sociais, abriu-se um novo espaço na internet para as empresas. Segundo dados do Instituto Brasileiro de Opinião Pública e Estatística, Ibope (2010), em 2010 a maioria dos consumidores já aprovava as empresas que usavam as redes para divulgarem seus produtos e serviços, como também para se comunicarem com seus consumidores. Em setembro de 2012, um estudo também realizado pelo Ibope (2012), mostrou que as redes sociais e outras páginas com foco no conteúdo produzido pelos usuários haviam crescido $11,6 \%$ em comparação com setembro de 2011.
A rede social virtual é uma forma rápida e barata de se estreitar o relacionamento com os consumidores e gerir a imagem da marca. Além disso, permite a difusão de informações pelo boca-a-boca entre as pessoas, gerando publicidade, mesmo que indireta, para a empresa. O boca a boca, buzz marketing ou marketing viral, acaba tendo muito mais poder na internet. $\mathrm{O}$ nome "viral" deriva justamente da propagação similar à transmissão de um vírus de computador (COBRA; BREZZO, 2010).

Cobra e Bezzo (2010) defendem que a internet e as redes sociais virtuais deixaram de ser apenas uma opção para as organizações que desejam entender seu consumidor, especialmente em determinados tipos de negócio. Entretanto, o uso das redes sociais virtuais pelas empresas envolve estabelecer uma estratégia que vá ao encontro do posicionamento de imagem desejado para a marca. Ao se criar uma página nessas redes, a empresa deve ter em mente algumas questões: o objetivo da página; o público que se quer atingir; a linguagem, conteúdo, abordagem, freqüência e nível de interação que serão utilizados; e o resultado esperado (CASTRO, 2012). Muitas empresas, por não pensarem nessa estratégia, encontram dificuldades para agir no ambiente das redes sociais.

Uma das mais famosas redes sociais da atualidade, o Facebook foi criado em 2004 pelo americano Mark Zuckerberg. Possui mais de 900 milhões de usuários mensais 
ativos, incluindo páginas de perfis pessoais, de bandas musicais, celebridades, empresas, etc. O Facebook foi a rede social mais visitada pelos brasileiros em fevereiro de 2013, com $65,03 \%$ da preferência dos usuários (CARREIRA, 2013). Entre as páginas de empresas no Facebook, chama a atenção a quantidade de lojas de moda que utilizam a rede social como forma de publicidade e interatividade com os clientes. De acordo com a pesquisa da ZipCode, divulgada pela versão online da revista Exame (2012), o setor de moda é o que mais interage em ações digitais, com um índice de 25,5\%, seguido pelo de eletrônicos e de comunicação.

Destaca-se que a moda é um dos instrumentos mais poderosos que as pessoas usam para se comunicar (MIRANDA, 2007).

A busca por individualidade e integração social leva os indivíduos a usarem vestuários próprios como expressão de identidade. Assim, as empresas do ramo da moda devem usar estratégias que atinjam os valores do consumidor, levando-o a ver a roupa como extensão de sua auto-imagem. Nesse ponto, entra a função do marketing. Cobra (1997) discorre como as empresas em geral, em especial as que atuam nos negócios da moda, vêm sofrendo impactos que as obrigam a rever sua forma de atuar, suas linhas de produtos, seus canais de distribuição e suas estratégias em geral. Ainda, segundo Cobra (1997), para se fazer marketing na moda é preciso analisar e entender as influências ambientais - como a tecnologia - a fim de se obter vantagens competitivas.

Nessa linha de raciocínio, é necessário conhecer as estratégias de marketing no ambiente das redes sociais virtuais de empresas do ramo da moda, baseando-se, principalmente, nos construtos: relacionamento com consumidoras, comunicação de marketing e suas novas tendências e marca. Desse modo, este trabalho tem como proposta pesquisar o uso do Facebook e de redes sociais virtuais para a promoção de uma marca de moda. A empresa escolhida é a “Amicci”, loja de moda que está no mercado desde 2009 e que utiliza o Facebook, além de outras redes sociais, como ferramenta de marketing. A pergunta que direcionou o estudo foi: "Quais as estratégias de marketing usadas pela Amicci no Facebook?". Acredita-se que a presente pesquisa é relevante, pelo fato dos estudos da contribuição das redes sociais como estratégia de marketing serem incipientes, principalmente na área de moda feminina.

Pretendeu-se com isso descobrir como a página do Facebook de uma loja de moda feminina de Belo Horizonte é usada para a estratégia de marketing, considerando principalmente as questões do relacionamento com clientes, de comunicação e da marca. Espera-se que esse estudo seja pertinente para o posterior aperfeiçoamento das ações da empresa e futuras pesquisas na área. 
Objetivou-se, ainda: verificar a percepção da estratégia de marketing no Facebook pela ótica da empresa e pela ótica das consumidoras; analisar o uso do Facebook no relacionamento com consumidoras e na comunicação de marketing e suas novas tendências; analisar o marketing no Facebook considerando o contexto da marca.

\section{MARKETING, RELACIONAMENTO,} REDES SOCIAIS VIRTUAIS E MODA

O marketing está presente em todo tipo de negócio, desde empresas e locais de lazer, até em escolas (KOTLER; ARMSTRONG, 2007). O papel geral do marketing é, basicamente, o de prolongar a vida útil das organizações, criando maneiras atrativas de suportar a ação da concorrência e procurando atender satisfatoriamente os clientes (COBRA; RIBEIRO, 2000).

O composto de marketing é utilizado para o desenvolvimento de estratégias de marketing. Dentro desse composto existem dois modelos: o dos 4 P's - visto pela ótica da empresa e criado pelo professor E. Jerome McCarthy - e o dos 4 C's - visto pela ótica do consumidor e criado pelo professor Robert Lauternburn (GABRIEL, 2010). O modelo dos 4 P's estabelece: o produto (aquilo que satisfaz a necessidade ou desejo do público); o preço (que estabelece as condições de troca); a praça (local em que a troca acontecerá) e a promoção (forma de comunicação para o público sobre o produto, preço e praça). Já o modelo dos 4 C's é o correspondente ao modelo dos 4 P's porém, como foi dito, visto pelo ponto de vista do consumidor. Ele estabelece: o cliente (do produto); o custo (para obter o produto); a conveniência (onde o consumidor pode escolher o produto) e a comunicação (nesse caso, mais ampla do que a promoção e envolvendo o consumidor) (GABRIEL, 2010).

Gabriel (2010) discorre que devido às novas plataformas e canais de comunicação que surgiram, ficou bem mais difícil, considerando o composto de marketing, impactar os consumidores. Dependendo do contexto, as pessoas são fragmentadas em termos de mídia, como também em relação as suas necessidades e desejos. A partir disso, surge a necessidade de desenvolver duas questões essenciais dentro da estratégia de marketing: o marketing de relacionamento e a comunicação de marketing, atentando para suas novas tendências. A questão do relacionamento é uma das mais importantes para o marketing. Todavia, a concepção de marketing relacional só foi gerada em 1982 por Leonard Berry (COBRA; BREZZO, 2010) e ganhou destaque em meados da década de 1990. Sob esta perspectiva, o marketing de relacionamento é uma área relativamente nova para os profissionais de marketing.

O marketing relacional possui duas subáreas: o relacionamento entre organizações 
e seus clientes individuais e o relacionamento entre organizações - marketing business-tobusiness (ROCHA; LUCE, 2006). Entretanto, Rocha; Luce (2006) dizem que "o termo 'marketing de relacionamento' acabou se impondo para designar o campo de estudos que analisa os relacionamentos entre as organizações e seus clientes (...)” (p.87). Apesar do marketing de relacionamento possuir muitas definições, apresentações, interpretações e práticas, ele busca, basicamente, à manutenção de clientes fiéis, lucrativos e duradouros (YAMASHITA; GOUVÊA, 2010). Para que isso aconteça, é necessário que haja o desenvolvimento e administração de parceria e confiança com os consumidores durante toda a vida (GORDON, 1998).

Assim, uma questão relevante para o marketing de relacionamento é a importância de se ouvir os clientes, não só os atuais e que já conhecem e fazem uso da marca, como também os clientes em potencial e os clientes em poder da concorrência, não conquistados ou perdidos (YAMASHITA; GOUVÊA, 2010). Apesar disso, mais do que conquistar novos clientes, a premissa do relacionamento consiste em manter o cliente já existente, instituindo uma conexão com o mesmo.

O boom da internet permitiu que o relacionamento fosse trabalhado nesse tipo de ambiente, já que a interação e o estreitamento de laços com os consumidores são facilitados. Gabriel (2010) afirma que a internet e as redes sociais virtuais são as grandes alavancas do relacionamento entre empresa e clientes, porque as ações online precisam contar com habilidades desse tipo de marketing. Nesse ínterim, a internet "é um importante espaço para a aplicação de estratégias de relacionamento com os públicos de organizações" (POSTAL, 2011) e, assim, se faz necessário entender como a empresa utiliza essa ferramenta para se relacionar com clientes preferenciais. Salienta-se que as mídias de comunicação de marketing tradicionais, relacionadas à publicidade em massa, como a televisão e o rádio, já há alguns anos vêm perdendo eficácia (VAZ, 2011). A necessidade do consumidor de se sentir ativo, somada ao fornecimento de uma plataforma para estratégias empresariais, permitiu o crescimento da internet como componente do programa de comunicação (CRAVENS; PIERCY, 2007).

O desenvolvimento da internet como um canal de comunicação virtual rápido, fácil e prático, acabou tornando-a um meio de resposta direta aos usuários, o que acarretou uma mudança no comportamento do consumidor. Nos recursos da internet encontram-se a criação de conhecimento e interesse, a disseminação e obtenção de informações, a construção da marca e a melhora do atendimento ao cliente (CRAVENS; PIERCY, 2007). Assim, o computador tem sido cada vez mais utilizado para desenvolver o marketing, dando origem 
ao chamado marketing digital (OGDEN; CRESCITELLI, 2007). O marketing digital nada mais é do que a aplicação dos conceitos de marketing no ambiente virtual, aproveitando todas as ferramentas que a internet oferece.

Nesse contexto surge o conceito de rede social virtual. Rede social não é algo novo, mas a internet possibilitou a criação de redes sociais virtuais, que acabaram funcionando como instrumentos para $\mathrm{o}$ marketing digital. O tema está tão em voga atualmente, que virou pauta tanto de ambientes acadêmicos quanto de ambientes profissionais (KOZESINSKI; et. al., 2011). As redes sociais virtuais são designadas, de acordo com Tomas et. al. (2012) como "sites de ligações sociais que permitem que os usuários se relacionem e compartilhem informações. Dentro dessas plataformas podem ser armazenados diversos formatos como fotos, vídeos, textos, etc. bem como diversas informações" (p.129).

Outro tema caro ao marketing e que também interessa a este estudo é o conceito de "marca", especialmente a imagem de marca no contexto da moda e da internet. Na gestão de uma marca dois conceitos são cruciais: sua imagem e seu posicionamento. "A imagem que a marca reflete é o espelho do consumidor" (COBRA; RIBEIRO, 2000, p.147). Com essa afirmação, Cobra; Ribeiro (2000) dizem que a marca consegue chegar até o consumidor pela imagem que transmite e pelo pensamento que desperta. $\mathrm{O}$ que a marca é, propriamente dita, deve ser proporcional a essas sensações. Caso isso não aconteça, a imagem da marca que foi construída ao longo do tempo acaba sendo distorcida. Já o posicionamento da marca tem a ver com a construção de desejos na mente das pessoas que possam ser realizados a partir de sua compra (COBRA; RIBEIRO, 2000). Desse modo, depende de atributos dos produtos e de seus valores tangíveis e intangíveis - representados por símbolos.

Para uma marca se firmar no mercado, é preciso um investimento em vários aspectos, como propaganda, promoção, entrega satisfatória de produtos e serviços, etc. Uma nova forma de publicidade para as marcas é o ambiente digital e, atualmente, "é quase impossível ignorar o elo entre a marca e a internet" (CRAVENS; PIERCY, 2007, p.286). Reis et. al. (2009) corroboram com esse pensamento, ao afirmarem que "entre as novas ferramentas utilizadas na construção e na manutenção de marcas, a internet, embora recente, se mostra importante. Desse modo, o gerenciamento da imagem da marca deve possuir relação com o gerenciamento das redes sociais virtuais e esse fato se torna mais importante ainda no ambiente da moda.

\subsection{Os novos desafios de marketing para a} Moda

A moda é um conceito dotado de ampla significação e simbolismo. A raiz 
etimológica da palavra, que segundo Cobra (2008) foi introduzida na língua italiana por volta de 1650, deriva do latim mos, que possui o significado de uso, costume, hábito, tradição, boas maneiras, moralidade, tipo, regra (COBRA, 2008). Para Miranda (2007), a moda é uma "forma de comunicação não verbalizada, estabelecida por meio das impressões causadas pela aparência pessoal de cada um" (p.3). A autora ainda acrescenta que "a marca de moda é carteira de identidade, não só desta era pós-moderna, como em todo decorrer da história da humanidade. $\mathrm{O}$ indivíduo expressa sua essência através de aspectos simbólicos presentes na aparência adornada" (MIRANDA, 2007, p.11). Em Cobra; Brezzo (2010) a moda é vista como "a mais esclarecedora vertente da busca de diferenciação social, por meio dos códigos que ela veicula acerca do status do usuário, seja para informar a sua postura social ou seus valores de veiculação a um grupo" (p.295). Assim, a explicação para muitas pessoas serem motivadas continuamente a estar na moda deriva de alguns fatores psicológicos, como: conformidade social, busca de variedade, criatividade pessoal e atração sexual (MELLO et. al., 2003).

Nesse sentido, Mello et. al. (2003) comentam que os valores pessoais dos indivíduos - que os guiam em seus comportamentos em sociedade - possuem papel crucial em suas orientações de consumo de moda. Entretanto, ao mesmo tempo em que os sujeitos buscam uma diferenciação através da moda, esta é uma forma de se tornar similar aos outros indivíduos, através da imitação, o que acaba proporcionando satisfação por não se sentir sozinho (MELLO et. al., 2003). Miranda (2007) também adota uma visão equivalente ao afirmar que a moda possui duas facetas singulares: a busca pela individualidade e a necessidade de integração social. O uso de determinado objeto da moda fomenta a relação entre o consumidor e o mundo, de maneira que a marca é ferramenta desta relação (MIRANDA, 2007).

A relação entre o Marketing e a Moda é estreita, sendo que a segunda se utiliza muito de conceitos e conhecimentos do primeiro. Várias áreas estão envolvidas nos negócios da moda: criatividade, produção, administração e marketing (COBRA, 2008). Para Cobra; Brezzo (2010)

\footnotetext{
A relação entre marketing e negócios da moda é apenas uma maneira de compreender a forma como a moda estimula o consumo de determinados produtos e o processo que eles demandam, desde a sua criação até a venda ao consumidor. (COBRA; BREZZO, 2010, p.296)
} 
A estratégia de marketing deve saber analisar as influências ambientais sobre os negócios da moda da empresa, a fim de obter vantagens competitivas que a concorrência não tenha. Segundo Cobra (1997), são quatro os fatores que afetam o ambiente da moda: (1) fatores demográficos, ecológicos e psicológicos; (2) fatores econômicos; (3) fatores sociológicos e (4) fatores ligados à atitude dos consumidores.

Uma das novas tendências do comércio varejista de moda é não se restringir ao espaço físico da loja, mas também ao marketing virtual (Cobra; Brezzo, 2010). Isso acontece porque o comportamento do consumidor "é o grande termômetro do sucesso empresarial" (COBRA, 2008, p.58) e as empresas vêm percebendo que o advento da internet mudou as diretrizes desse comportamento.

No contexto do marketing digital, as redes sociais virtuais são uma ótima oportunidade para as empresas do setor de moda ganharem uma grande exposição. Através da página virtual na rede, as empresas conseguem acompanhar ações de lojas concorrentes ou analisar o número, perfil e comentários de usuários que os "curtem" (SOUZA; SOARES, 2012). A rede social Facebook é um dos meios para as lojas de moda divulgarem os lançamentos de novas coleções, criar promoções, eventos e, a partir disso, ver a repercussão gerada entre as consumidoras. Além disso, permite interação e conhecimento do que as consumidoras estão pensando a respeito da marca.

\subsection{A Amicci Moda}

A Amicci é uma loja de moda de Belo Horizonte, localizada no bairro Savassi. A loja conta com um espaço físico pequeno, porém capaz de chamar a atenção do público que a visita. Entretanto, por se localizar dentro de uma galeria, a Amicci não possui visibilidade para pessoas que transitam na rua.

Os primeiros movimentos para sua criação surgiram em 2009 quando duas amigas de faculdade, formadas em moda, decidiram abrir uma confecção de roupas e acessórios para o público feminino jovem. Até então, a loja não possuía ambiente físico e as amigas levavam as peças de roupa na casa das pessoas interessadas. Nessa época, o único meio de divulgação para a marca era a rede social Orkut.

Em outubro de 2010, a loja física foi aberta no mesmo lugar em que está localizada até hoje, atendendo o comércio atacado e varejo - que é o forte da marca. Apesar da faixa de preços ser mediana, como a marca possui muita informação de moda, consegue atingir um público com boas condições financeiras - normalmente classes A e B. Atualmente, há apenas uma proprietária das duas iniciais (a que foi entrevistada para este estudo). 
No que se refere à inserção da marca na internet, como foi dito, a Amicci participava somente da rede social Orkut, que agora já caiu em desuso pelos usuários da internet. Também foi criado um blog logo no início das atividades, todavia o mesmo só teve algumas postagens e não foi pra frente. Hoje em dia, a Amicci participa de duas redes sociais virtuais: Instagram e Facebook, sendo esta última o objeto de análise desta pesquisa.

\section{METODOLOGIA}

A pesquisa foi de natureza qualitativa e do tipo exploratória. A escolha de uma abordagem qualitativa ocorreu em função da proposta de pesquisa, dos recursos disponíveis e, principalmente, pelo fato da pesquisa qualitativa captar nuances que um estudo quantitativo não conseguiria (GIL, 1999). Portanto, no contexto deste estudo o objetivo exploratório é mais adequado, uma vez que o uso das redes sociais virtuais como estratégia de marketing é recente e objeto de poucas pesquisas. A escolha do objeto do estudo de caso foi feita por julgamento (GIL, 1999). A Amicci foi escolhida por possuir características de interesse para a composição do estudo e por se mostrar disposta a colaborar com a realização da pesquisa.

A coleta de dados ocorreu entre abril e maio de 2013 e foi feita por meio de entrevistas com a proprietária da Amicci e com sete usuárias do Facebook que curtem a página da loja, observação e análise. Em estudos desse tipo, as entrevistas consistem em algumas das mais importantes fontes de informação (YIN, 2001). Elas foram feitas a partir de um roteiro semi-estruturado, previamente elaborado, com questões abertas e baseadas nos conceitos dos autores mencionados na seção Referencial Teórico. Foram também utilizadas algumas imagens da página no Facebook, que ajudam a corroborar as conclusões.

Entrevistou-se a proprietária, já que a mesma é a responsável por lidar diretamente com a página do Facebook da loja. Já em relação às usuárias que curtem a página, três foram escolhidas por conveniência e as outras aleatoriamente. Salienta-se que o número de entrevistadas foi definido conforme o porte da loja, o perfil de clientes e a operacionalidade da pesquisa - neste caso, por não se tratar de pesquisa quantitativa, seria equivocado o termo amostragem (BAUER; AARTS, 2007). Trata-se, portanto, da construção de um corpus: "uma coleção finita de materiais, determinada de antemão pelo analista, com (inevitável) arbitrariedade, e com a qual ele irá trabalhar (BARTHES, 1967: 96 in BAUER; AARTS, 2007)". Neste caso, foi um número relativamente pequeno de entrevistadas, mas julgou-se que isso não comprometeria a qualidade e a relevância da pesquisa.

A entrevista com a proprietária foi realizada na loja física e utilizou como 
referência o instrumento de pesquisa feito por Souza; Soares (2012), modificado pela autora para se adequar aos propósitos dessa pesquisa. As perguntas buscaram, primeiramente, conhecer o histórico e a trajetória da Amicci para, depois, abordar as práticas de marketing no Facebook da empresa (Quadro 1).

As entrevistas com as usuárias que curtem a página foram realizadas via Facebook e utilizou instrumento de pesquisa elaborado pela autora. A intenção foi conhecer a visão dessas usuárias a respeito da página da Amicci, nos quesitos relacionamento, comunicações, imagem e posicionamento da marca. $\mathrm{O}$ roteiro de entrevistas foi estruturado da seguinte forma (Quadro 1):

Quadro 1: Roteiros de Entrevista

\begin{tabular}{|c|c|}
\hline $\begin{array}{l}\text { Roteiro de Entrevista } \\
\text { (Proprietária) }\end{array}$ & $\begin{array}{l}\text { Roteiro de Entrevista } \\
\text { (Clientes) }\end{array}$ \\
\hline $\begin{array}{l}\text { 1) Histórico da Amicci } \\
\text { Moda: a) Fundação; b) } \\
\text { Trajetória; c) Atividades } \\
\text { 2) Marketing: a) } \\
\text { Promovem alguma ação } \\
\text { de marketing que não seja } \\
\text { no meio digital? Quais?; } \\
\text { b) Possui site ou blog?; c) } \\
\text { Quais as redes sociais que } \\
\text { já fez e/ou faz parte? } \\
\text { 3) Facebook: a) Quando } \\
\text { surgiu a ideia de possuir } \\
\text { uma página } \\
\text { Facebook?; b) O que a }\end{array}$ & $\begin{array}{l}\text { 1) Desde quando curte a } \\
\text { página no Facebook da } \\
\text { Amicci Moda? Qual ou } \\
\text { quais motivos te levaram } \\
\text { a curtir a página? } \\
\text { 2) Já indicou a página da } \\
\text { loja no Facebook para } \\
\text { alguma amiga ou contato } \\
\text { da rede? } \\
\text { 3) Em relação aos posts } \\
\text { da loja na página do } \\
\text { Facebook, que imagem da } \\
\text { marca você acha que eles } \\
\text { passam? Acha que essa }\end{array}$ \\
\hline
\end{tabular}

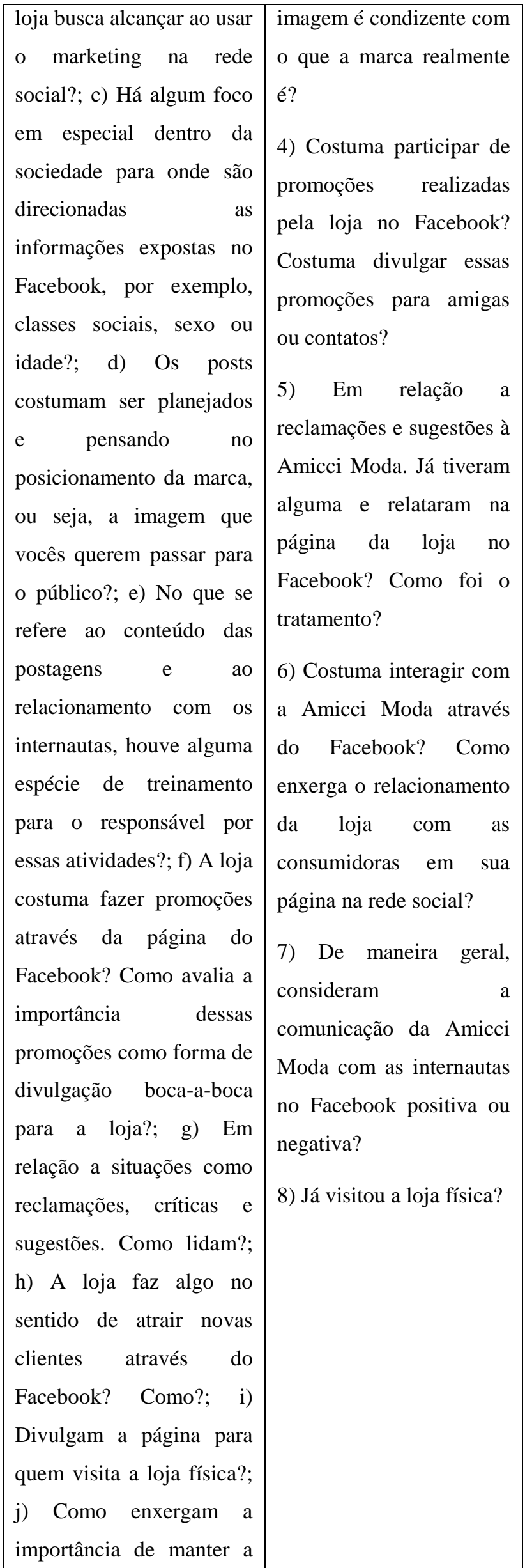

loja busca alcançar ao usar social?; c) Há algum foco em especial dentro da classes sociais, sexo ou costumam ser planejados seja, a imagem que ao conteúdo das relacionamento com os internautas, houve alguma para o responsável por através da página do Facebook? Como avalia a importância promoções como forma de para a loja?; g) Em relação a situaçoes como reclamações, críticas sugestões. Como lidam?; sentido de atrair novas através do Facebook? Como?; i) Divulgam a página para m visita a loja física? importância de manter a 


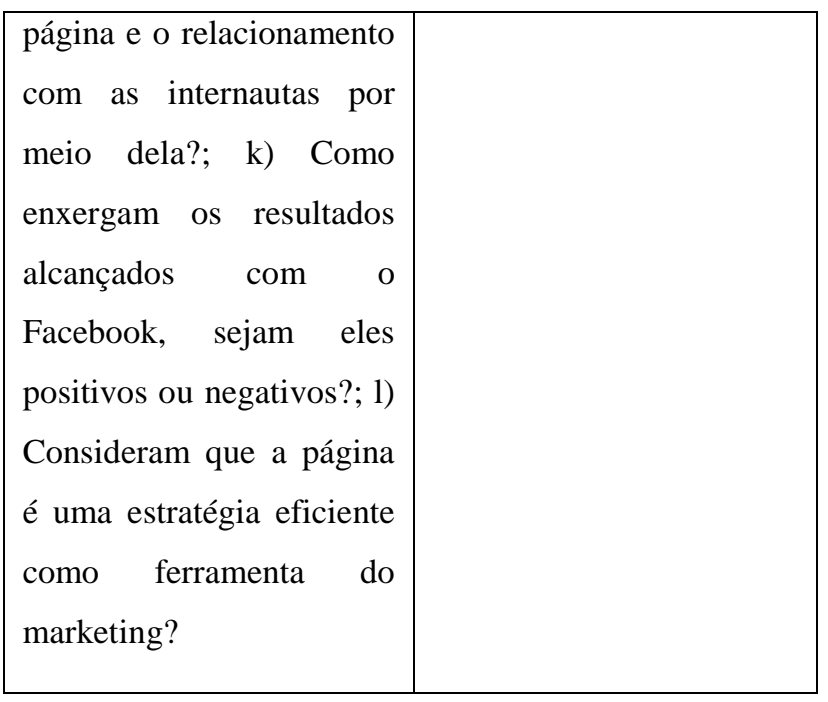

Fonte: Os autores.

Posteriormente, foi feita a exploração do material e interpretação do conjunto de respostas das entrevistadas que, segundo Gil (1999), objetivam tornar os dados válidos e significativos. As respostas obtidas com a Amicci foram comparadas com as respostas das usuárias. De acordo com Gil (1999), quando informações obtidas são confrontadas com informações já existentes, podem-se chegar a boas conclusões.

A observação simples e semanal da página da loja na rede social foi útil e serviu para amparar o estudo, por permitir algumas constatações e servir de contraponto com o que foi relatado nas entrevistas. Gil (1999) caracteriza esse tipo de observação como espontânea, mas "que exige um mínimo de controle na obtenção dos dados" (GIL, 1999, p. 111). Os resultados alcançados com o tratamento dos dados foram interpretados levando-se em consideração o contexto do setor estudado.

\section{APRESENTAÇÃO E ANÁlISE DOS RESULTADOS}

A Amicci criou a página de sua marca no Facebook em março de 2012. Entretanto, a marca já possuía uma conta na rede - no formato de perfil pessoal - logo que a "febre" do Facebook começou no Brasil, em meados de 2010. Sua proprietária contou que a idéia de possuir uma conta no Facebook surgiu para divulgação das peças e captação de consumidoras. Com esse perfil pessoal, a Amicci adicionava muitas pessoas em sua rede de contatos, o que vai contra as "regras" do Facebook para esse tipo de conta. Como o número de contatos adicionados pela empresa chegou a um limite, o Facebook retirou o perfil da Amicci do ar. Assim, surgiu a necessidade de criar uma página comercial para a marca dentro da rede social.

Em sua atual página, a Amicci se define como "uma marca exclusiva, que traduz as tendências da moda com personalidade, qualidade e beleza para atender mulheres modernas, exigentes e sofisticadas". A página funciona como uma "vitrine" para a Amicci, pois é a única estratégia de comunicação de marketing da loja, segundo relatos da proprietária. Fora isso, a única ação de comunicação de marketing que a empresa promove é presentear blogueiras de moda mulheres que publicam textos na Web com novidades e tendências do mercado - com peças da marca. Porém, a proprietária 
considera essa atitude "um tiro no escuro, pois nem sempre isso rende posts ou então a blogueira só agradece por ter recebido as peças" (Figura 1).
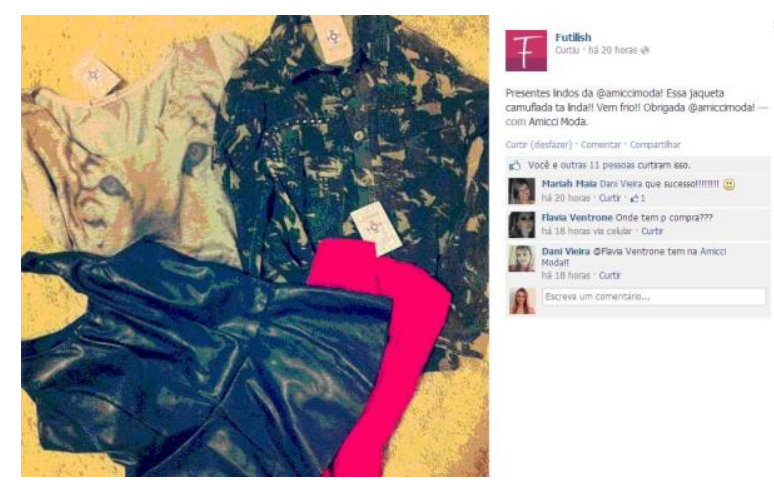

Figura 1 - Amicci presenteando blogueira Constanza Fernandes, do blog de moda Futilish

Fonte: Facebook (Acesso em 04 de abril de 2013).

No início da coleta de dados, havia 9.199 pessoas “curtindo" a página da Amicci no Facebook (Figura 2). Até o momento final da realização dessa pesquisa, 10.035 pessoas haviam "curtido" a página da Amicci na rede social (Figura 3). Esse crescimento demonstra como o Facebook auxilia a divulgação da marca. Além disso, é importante ressaltar que a partir do momento que uma pessoa "curte" uma página no Facebook, é porque esta chamou sua atenção ou tem algo do seu interesse.

Dentre as entrevistadas, quatro usuárias já indicaram a marca Amicci no Facebook para amigas ou contatos da rede. Mas é interessante observar que, mesmo quando essa indicação não é feita, uma pessoa pode se interessar pelo conteúdo da página simplesmente por ver que um de seus contatos também se interessou, conforme pode se notar no trecho a seguir: "Algumas amigas começaram a seguir porque viram que eu sigo, mas nunca indiquei diretamente não" (Entrevistada 6).

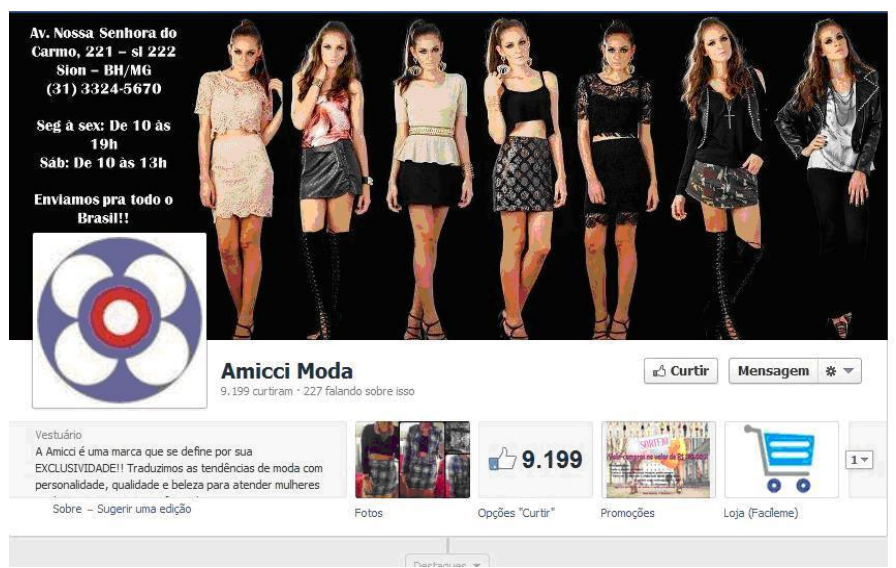

Figura 2 - Página da Amicci no Facebook em abril de 2013

Fonte: Facebook (Acesso em 01 de abril de 2013).

Em 28 de abril de 2013, a Amicci contava com dezesseis álbuns de fotos no Facebook, sendo que, geralmente, os mais “curtidos" e comentados são os que se referem a lançamentos de coleções: Fotos da Linha do tempo (com 225 fotos); OUTONO/INVERNO 2013 (com 87 fotos, 11 comentários e 124 pessoas curtindo); Instagram Photos: @amiccimoda (com 190 fotos, 8 comentários e 90 pessoas curtindo); Fotos de capa (com 21 fotos); LIQUIDA AMICCI (com 74 fotos, 5 comentários e 28 pessoas curtindo); LIQUIDAÇÃO PROGRESSIVA (com 80 fotos, 5 comentários e 27 pessoas curtindo); Looks para REVEILLON (com 24 fotos, 12 comentários e 52 pessoas curtindo); Amicci 
por aí... Verão 2013 (com 32 fotos e 3 pessoas curtindo); Alto-Verão 2013 (com 46 fotos, 10 comentários e 105 pessoas curtindo); Amicci por aí... (com 210 fotos, 3 comentários e 26 pessoas curtindo); Primavera/Verão 2013 (com 74 fotos, 13 comentários e 49 pessoas curtindo); PROMOÇÃO AMICCI POR AÍ... (com 17 fotos e 2 pessoas curtindo); Outono/Inverno 2012 (com 73 fotos, 12 comentários e 53 pessoas curtindo); Looks para Phenomenal Black (com 21 fotos, 3 comentários e 13 pessoas curtindo); LIQUIDA AMICCI - 50 à 70\% de desconto!! (com 55 fotos e 8 pessoas curtindo); Verão 2012 -FREEDOM(com 81 fotos, 1 comentário e 9 pessoas curtindo).

As atualizações na página ocorrem diariamente e, às vezes, até mais de uma vez ao dia. São publicações que mostram a chegada de peças da nova coleção; "look do dia" - produções de moda com peças da loja; dicas de tendência; liquidações e promoções, etc. A responsável pelas publicações e pelos looks é a proprietária, pois, segundo a mesma, "não teve coragem de delegar essa função ainda, além da outra funcionária não gostar desse tipo de coisa".

Foi relatado que as publicações costumam ser planejadas e pensando no posicionamento e imagem da marca: uma loja com informações de moda. De fato, observase que até mesmo a linguagem utilizada é planejada pensando no público-alvo da marca
- feminino jovem - e em maneiras de criar uma identidade com o mesmo (Figura 5).

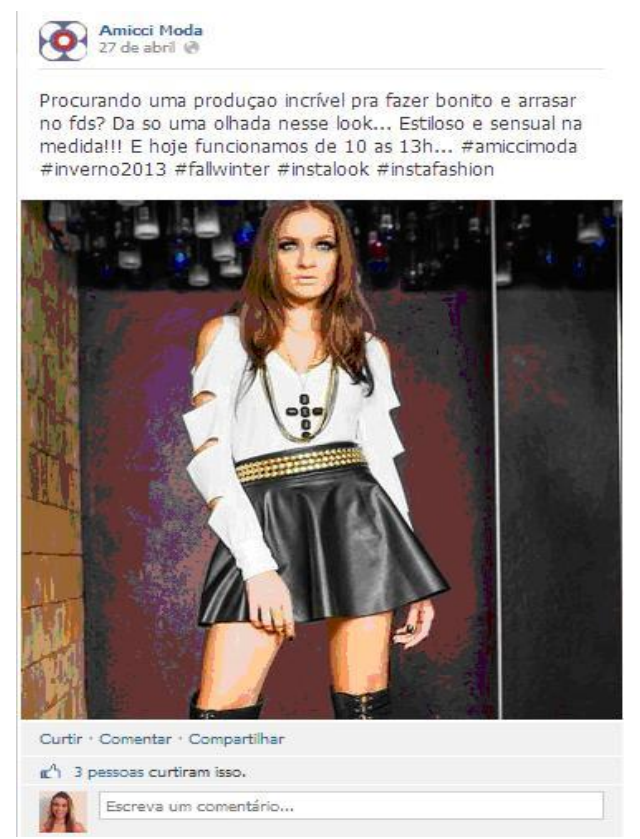

Figura 3 - Publicação na Amicci em sua página no Facebook

Fonte: Facebook (Acesso em 05 de maio de 2013).

As entrevistas com as usuárias fortalecem essa questão. Das sete entrevistadas, todas afirmaram que a imagem que a marca passa no Facebook é condizente com o que a marca realmente é. Algumas palavras utilizadas para caracterizar essa imagem foram: "marca jovem e despojada" (Entrevistada 1); "moda atualizada" (Entrevistada 2); “loja descolada, com roupas de moda" (Entrevistada 5); "marca jovem, antenada nas tendências" (Entrevistada 6); "loja inovadora, antenada às novidades da moda" (Entrevistada 7). Esses relatos, indo de acordo ao pensamento de Vaz (2011), demonstram que o decurso da construção de 
imagem e posicionamento da marca Amicci na rede social é eficiente.

A página da Amicci na rede social é uma forma de comunicação entre a loja e as consumidoras, já que é possível ficar por dentro das últimas novidades e há a possibilidade de interação por meio do mural e inbox (mensagem privada), quando alguma usuária solicita informação. Nas palavras da proprietária: "a internet está crescendo cada dia mais no mundo, é o melhor meio de comunicação. As redes sociais, no geral, são fundamentais nos negócios da Amicci”. Assim, no que tange às relações e interação, foi analisado que a Amicci possui o intuito de estreitar o relacionamento com as consumidoras, a partir do uso do Facebook, pois, no período observado, respondeu a todos os questionamentos e perguntas feitos em sua página. Mesmo quando não houve uma resposta visível a todos, subentende-se que a loja procurou responder o questionamento, pois "curtiu" o que foi postado pela consumidora; provavelmente, a resposta se deu via inbox. Conforme pode ser visto nos trechos a seguir.

- "Sempre que quero saber o preço de algum produto, entro em contato pelo inbox. Elas sempre me atendem prontamente, a impressão que passam é a de que são bastante atenciosas" (Entrevistada 1); "Costumo curtir e comentar sobre as coisas que gosto, faço reservas pelo Facebook também. O relacionamento é de interação, sempre somos respondidas" (Entrevistada 2); "Interagi apenas quando quis comprar uma blusa e elas foram atenciosas. Pelo que vejo, elas tratam todas muito bem e com muita atenção" (Entrevistada 3); "Já perguntei sobre algumas peças e sempre foram cordiais, logo me enviaram a resposta" (Entrevistada 4); “Interajo só quando preciso saber o valor de alguma peça. Acredito que o tratamento seja igual para todas consumidoras, no geral a pessoa responsável pela página é sempre atenciosa" (Entrevistada 6).

Apesar de umas das entrevistadas dizer que nunca interagiu com a loja, a mesma afirmou o seguinte: "Acredito que o relacionamento das consumidoras com a loja seja ótimo, pois sempre vejo clientes curtindo e fazendo comentários positivos nos posts da loja" (Entrevistada 7). A partir disso, a observação da página e os trechos anteriores corroboram com o que foi relatado na entrevista pela Amicci, que considera o Facebook "fundamental, uma forma de aproximar o cliente da empresa". Quando questionada sobre o relacionamento com as internautas, a proprietária respondeu: "procuro responder todo mundo, faço questão de responder um por um".

Até mesmo em situações de críticas, reclamações ou sugestões, a marca age com cordialidade (Figura 6); além disso, não costumam apagar esse tipo de publicação, como outras empresas fazem. "Tento 
responder o mais educadamente possível, mas não costumo ter muito problema com isso. Normalmente são pessoas que reclamam de algum dano na peça, pedra do colar que soltou, mas respondo que podem vir trocar a peça”. Nenhuma das entrevistadas teve críticas, reclamações ou sugestões para a Amicci. Pelo contrário, algumas chegaram a elogiar o tratamento. "Nunca fiz nenhum tipo de reclamação, mas noto que a marca está sempre melhorando em algo" (Entrevistada 1) e "A dona da loja é super atenciosa, creio que seria contornado se houvesse algum problema" (Entrevistada 2).

Outro cuidado da Amicci é o de informações incorretas em sua página no Facebook. Já houve casos em que a Amicci informou o preço de determinada peça na rede social para uma consumidora, mas quando a mesma foi à loja física, o preço da peça era outro, superior. Em situações como essa, a empresa averigua a situação e, caso tenha cometido um equívoco, reconhece o erro e passa a peça pelo preço que havia informado anteriormente. Isso demonstra como a loja busca satisfazer o consumidor e evitar futuras reclamações. Como foi dito anteriormente, algumas das atualizações na página da Amicci no Facebook consistem em promoções para concorrer a vale-compras na loja. Os requisitos básicos para participar costumam ser: "curtir" a página da loja, "curtir" a publicação da promoção, compartilhar em seu perfil pessoal e marcar amigas(os) (Figura 7).
A opção de compartilhamento de conteúdo faz com que todos os amigos de determinado usuário da rede tomem conhecimento de algo que chamou sua atenção e foi compartilhado. Um segundo usuário pode se interessar por esse conteúdo e também compartilhá-lo, gerando uma difusão ascendente da informação. A proprietária confirmou esse fato, ao dizer que essas promoções acabam dando maior visibilidade para a Amicci no Facebook, sendo uma forma de divulgação boca-a-boca virtual. Nessa situação, a consumidora se torna a emissora da mensagem para a loja.

Das sete usuárias entrevistadas, todas afirmaram que já participaram de alguma promoção da Amicci no Facebook. Mesmo que o compartilhamento da promoção no perfil pessoal seja considerado requisito básico para participar dessas promoções, quatro usuárias disseram que ainda costumam comentar com amigas e contatos a respeito. Essa é uma grande vantagem para a Amicci, pois a indicação de determinado conteúdo por uma amiga é considerada mais confiável do que se viesse da própria loja. Outro fato mencionado por Danielle em relação à comunicação na rede social e que gera divulgação para a marca é a possibilidade da publicidade paga. Essa ferramenta disponível para empresas no Facebook permite que a Amicci apareça como página sugerida para os contatos de quem a curte. Em promoções e lançamentos de coleção, a empresa costuma 
utilizar esse tipo de publicidade a fim de gerar maior divulgação.

Como, normalmente, quem visita o espaço físico já conhece a página da marca no Facebook, a proprietária conta que não costuma divulgá-la, apenas pede para continuar acompanhando. Entretanto, o inverso não é verdadeiro. Como comentado por Oliveira (2013), apenas o fato da usuária “curtir" a marca Amicci no Facebook não garante que ela vá visitar efetivamente a loja física. Essa informação foi comprovada pelas entrevistas, pois apenas quatro das sete usuárias afirmaram que já foram à loja física da Amicci, sendo que todas as sete, quando questionadas a respeito da comunicação de marketing da marca na rede social, a consideraram positiva. Ou seja, mesmo a visão das internautas a respeito da comunicação da marca sendo boa, nem sempre isso leva ao consumo efetivo na loja.

As entrevistadas 6 e 7, que nunca foram à loja física, acrescentaram que acreditam que a comunicação na rede social ajuda às vendas e o relacionamento com as clientes. Já a entrevistada 3, que é consumidora da Amicci, relatou: "Olhando pelo lado da comunicação/publicidade, acho que elas poderiam usar menos posts amadores e mais conceituais".

No que tange aos resultados alcançados com o Facebook, a proprietária os considera: "positivos e todos revertidos em venda. O Facebook acaba proporcionando um feedback das clientes, o que elas gostam mais, o que elas estão querendo. Quando faz publicação, pela quantidade de 'curtidas' $e$ comentários, dá pra ter noção que aquilo ali chamou atenção". Além disso, o Facebook fornece para quem possui página de negócios a visualização de um histórico: quantas pessoas curtiram determinada publicação, a faixa etária, a região geográfica, entre outras informações, o que permite a loja criar uma espécie de perfil das "curtidoras" da página e promover estratégias cada vez mais eficientes e segmentadas.

Desse modo, pode-se concluir que o Facebook é sim uma estratégia de comunicação de marketing eficiente no caso da Amicci, conforme atesta a proprietária: “ $O$ Facebook melhorou muito as vendas, em $100 \%$, é uma ferramenta que dá pra interagir muito mais. Quando ficamos sem a conta do perfil da loja, as vendas caíram muito”. A proprietária ainda acrescenta que: “ $O$ Facebook é uma comunicação mais rápida. Outra coisa que facilita muito é que hoje em dia o Facebook está presente em forma de aplicativo até nos celulares, então nem precisa estar de frente para o computador pra ter acesso às informações".

\section{CONSIDERAÇÕES FINAIS}

Percebeu-se que a inserção da marca no ambiente virtual, com o uso do Facebook para sua estratégia de marketing - nos quesitos relacionamento com clientes, 
comunicação e gestão da marca - cria identificação com as consumidoras pesquisadas. A proprietária chega inclusive a afirmar que há uma relação direta entre as ações de comunicação na mídia e o aumento de vendas.

A marca possui uma página na rede social bem estruturada, conforme as clientes, e a utiliza para sua publicidade de maneira satisfatória. O Facebook, para a Amicci, funciona como uma espécie de "vitrine", já que a loja física não possui muita visibilidade e, assim, a rede social se torna um dos únicos meios de conhecimento a respeito da marca. Foi observado que a postura da Amicci, a respeito da interação com consumidoras no Facebook, vai ao encontro ao que é proposto pelo marketing de relacionamento. De fato, além da rede social já contribuir para uma atitude de interação entre pessoas, a marca procura estreitar a ligação, tratando as usuárias de forma igualitária e respondendo a todas.

No que tange a comunicação, a marca consegue, por meio do Facebook, passar uma imagem e posicionamento condizentes com sua realidade, que é voltada para o público jovem e feminino. Ainda na questão da comunicação, constatou-se que a rede social funciona como plataforma de divulgação boca-a-boca entre o público, já que a maioria das usuárias costuma compartilhar a página da marca, assim como promoções efetuadas pela mesma, para amigos e contatos. Além disso, quando se "curte" ou compartilha algo no Facebook, a usuária está mostrando para os seus contatos o seu "rótulo" e amigas podem se interessar por esse conteúdo. Assim, essas amigas podem vir a se tornar futuras consumidoras da loja, simplesmente pelo fato da amiga - que é uma pessoa confiável - ter indicado; ou porque a amiga curtiu e isso incitou um desejo na outra.

Como aperfeiçoamento para a Amicci, sugere-se o ponto levantado por uma das usuárias entrevistadas, que é de o melhorar a publicidade da marca através do Facebook com publicações mais conceituais, ou seja, conteúdos mais aprofundados no universo da moda.

Para finalizar, salienta-se que este estudo é de natureza exploratória e qualitativa e carece de análises mais aprofundadas, especialmente sobre a relação que houve em investimento em comunicação e retorno de vendas, utilizando, por exemplo, dados secundários da loja e do próprio Facebook. Há também outras possibilidades metodológicas interessantes para esta pesquisa, em estudos de cunho descritivo, que poderiam contribuir para conclusões mais generalizáveis. Esta pesquisa, contudo, mostra uma tendência interessante a ser investigada no campo da moda feminina jovem feminina e nesse sentido atendeu às expectativas inicialmente geradas. 


\section{REFERÊNCIAS BIBLIOGRÁFICAS}

ANDRADE, Josmar; MAZZON, José

Afonso; KATZ, Sérgio. Boca-a-boca

eletrônico: explorando e integrando conceitos

de marketing viral, buzz marketing e word-ofmouse. In: ENCONTRO DE MARKETING DA ANPAD, 2006, Rio de Janeiro Anais... Rio de Janeiro: Anpad, 2006. Disponível em: <http://www.anpad.org.br/ema/2006/dwn/ema 2006-mkta-412.pdf $>$ Acesso em: 12 de abril de 2013.

BENTIVEGNA, Fernando Jucá. Fatores de impacto no sucesso do marketing boca-a-boca online. RAE, São Paulo, v.42, n.1, jan/mar. 2002, p.79-87.

BAUER, Martin; AARTS, Bas. A Construção do Corpus: um Princípio Para a Coleta de Dados Qualitativos. . In: BAUER, M. W.; GASKELL, G. Pesquisa Qualitativa com Texto Imagem e Som. Petrópolis: Vozes, 2007.

CARREIRA, Renan. Facebook foi a rede mais visitada no país em fevereiro. 2013. Disponível em:

<http://exame.abril.com.br/tecnologia/noticias /facebook-foi-a-rede-mais-visitada-no-paisem-fevereiro-2> Acesso em: 25 de março de 2013.

CASTRO, Mariela. Por onde começar uma estratégia de mídias sociais. 2012.

Disponível em:

$<$ http://exame.abril.com.br/rede-deblogs/midias-sociais/2012/10/22/por-ondecomecar-uma-estrategia-de-midias-sociais/> Acesso em: 25 março de 2013.

COBRA, Marcos. Algumas reflexões acerca do marketing da moda. RAC, São Paulo, vol. 4, Edição Light, 1997, p. $2-5$.

COBRA, Marcos. Marketing e moda. São Paulo: Senac, 2008.

COBRA, Marcos; BREZZO, Roberto. 0 novo marketing. Rio de Janeiro: Elsevier, 2010.
COBRA, Marcos; RIBEIRO, Áurea.

Marketing: magia e sedução. São Paulo: Cobra, 2000.

CRAVENS, David W.; PIERCY, Nigel F. Trad. José Carlos Barbosa dos Santos; Katia Aparecida Roque; Telma Regina Matheus. Marketing estratégico. São Paulo: McGrawHill, 2007.

EXAME. Moda é o setor que mais interage nas ações digitais. 2012. Disponível em: $<$ http://exame.abril.com.br/marketing/noticias /moda-e-o-setor-que-mais-interage-nas-acoesdigitais-diz-pesquisa> Acesso em: 25 de março de 2013.

GABRIEL, Martha. Marketing na era digital: conceitos, plataformas e estratégias. São Paulo: Novatec, 2010.

GIL, Antonio Carlos. Métodos e Técnicas de Pesquisa Social. São Paulo: Atlas, 1999.

GORDON, Ian. Marketing de

relacionamento: estratégias, técnicas e tecnologias para conquistar clientes e mantêlos para sempre. Trad. Mauro Pinheiro. São Paulo: Futura, 1998.

GUMMESSON, Evert. Trad. Marina Barbieri Campomar e Jonathan Hogan. Marketing de relacionamento total: gerenciamento de marketing, estratégias de relacionamento e abordagem da CRM para economias de rede. Porto Alegre: Bookman, 2005.

IBOPE. Many to Many: O Fenômeno das Redes Sociais no Brasil. 2010. Disponível em:

<http://www.ibope.com.br/maximidia2010/do wnload/Redes_Sociais.pdf $>$. Acesso em: 15 de março de 2013.

IBOPE. Sites de busca, portais e redes sociais foram os mais acessados no último mês. 2012. Disponível em: <http://www.ibope.com.br/ptbr/noticias/Paginas/Sites-de-busca-portais-eredes-sociais-foram-os-mais-acessados-noultimo-mes.aspx> Acesso em: 15 de março de 2013. 
KOZESINSKI, Ricardo; JR, Alberto de Medeiros, PEREZ, Gilberto. O uso das redes sociais virtuais como ferramenta de comunicação de marketing pelo mercado editorial. In: XIV SEMINÁRIOS DE ADMINISTRAÇÃO, 2011, São Paulo. Anais... São Paulo, SemeAd, 2011. Disponível em:

<http://www.ead.fea.usp.br/semead/14semead /resultado/trabalhosPDF/1153.pdf> Acesso em: 15 de março de 2013.

KOTLER, Philip. ARMSTRONG, Gary. Trad. Cristina Yamagami. Princípios de marketing. São Paulo: Pearson Prentice Hall, 2007.

MELLO, Sérgio Carvalho Benício de; LEÃO, André Luiz Maranhão de Souza; NETO, Arcanjo Ferreira de Souza. Que valores estão na moda? Achados muito além do efêmero. RAM, São Paulo, v. 4, n.2, 2003, p.117-134.

MIRANDA, Ana Paula Celso de. Por um sentido na vida: marcas de moda e a relação pessoa-objeto. In: ENCONTRO NACIONAL DOS PROGRAMAS DE PROGRAMAS DE PÓS-GRADUAÇÃO EM

ADMINISTRAÇÃO, 2007, Rio de Janeiro. Anais... Rio de Janeiro: Associação Nacional de Pós-Graduação e Pesquisa em Administração, 2007.

OGDEN, James R.; CRESCITELLI, Edson. Comunicação integrada de marketing: conceitos, técnicas e práticas. Trad. Cristina Bacellar. São Paulo: Pearson Prentice Hall, 2007.

OLIVEIRA, Solange. A relação ecommerce, moda e redes sociais. 2013. Disponível em:

$<$ http://ecommercenews.com.br/artigos/cases/ a-relacao-e-commerce-moda-e-redes-sociais $>$ Acesso em: 25 de março de 2013.

POMPÉIA, Rosário de. Planejar é mais que preciso! In: AYRES, Marcel; CERQUEIRA, Renata; DOURADO, Danila; SILVA, Tarcízio (orgs). \#Mídias Sociais:

Perspectivas, Tendências e Reflexões. 2010. Disponível em: <http://issuu.com/papercliq/docs/ebookmidias sociais> Acesso em: 29 de março de 2013.

POSTAL, Laura Casotti. Marketing de relacionamento nas redes sociais: um estudo da marca Melissa. 2011. Universidade Federal do Rio Grande do Sul. Disponível em: <http://www.lume.ufrgs.br/bitstream/handle/1 0183/31816/000785577.pdf?sequence $=1>$ Acesso em: 31 de março de 2013.

REIS, Clóvis; ZUCCO, Fabrícia Durieux; DAMBRÓS, Joana. A gestão colaborativa da marca nas redes sociais virtuais. REMark, São Paulo, v.8, n.2, jul/dez 2009, p.41-54.

ROCHA, Ângela da; LUCE, Fernando Bins. Relacionamentos entre compradores e vendedores: origens e perspectivas no marketing de relacionamento. RAE, São Paulo, v.46, n.3, Edição Clássicos, jul/set 2006, p. 87-93.

SOUZA, Francisco Junior Silva de; SOARES, Luan Felipe Vieira. $O$ marketing nas redes sociais: estudo de caso na empresa Loja Retro de Nova Venécia - ES. 2012. Faculdade Capixaba de Nova Venécia. Disponível em: < http://univen.noip.biz/listamono/monografias/Administra\%C3 \%A7\%C3\%A3o\%20e\%20An\%C3\%A1lise\% 20de\%20Sistemas/2012/O\%20MARKETING \%20NAS\%20REDES\%20SOCIAIS.pdf >

Acesso em: 23 de abril de 2013.

TOLEDO, Luciano Augusto; GOZZI, Sérgio; FEDICHINA, Marcio. O composto de marketing sob a ótica da internet.

Administração em Diálogo, São Paulo, n.6, 2004, p. 113-123.

TOMAS, Robson Nogueira; MESCHGRAHW, Rodolpho Pierre; ALCANTARA, Rosane Lúcia Chicarelli. As redes sociais e o comportamento de compra do consumidor: o reinado do "boca-a-boca" está de volta? REMark, São Paulo, v.11, n.2, maio/ago. 2012, p.124-151. 
VAZ, Conrado Adolpho. Os 8 P's do

marketing digital: o seu guia estratégico de

marketing digital. São Paulo: Novatec, 2011.

YAMASHITA, Sandra Sayuri; GOUVÊA,

Maria Aparecida. Marketing de

relacionamento: importância e implicações no

mercado consumidor. RAM, São Paulo, v.8, n.4, 2007, p.103-124.

YIN, Robert K. Trad. Daniel Grassi. Estudo

de Caso: Planejamento e Métodos. Porto

Alegre: Bookman, 2001. 